CARDIAC SPECIFIC ALPHA-MYYOSIN ANTIBODIES IN ALCOHOLIC LIVER DISEASE: AN IMMUNOLOGICAL ROLE IN ASYMPTOMATIC LEFT VENTRICULAR ENLARGEMENT?

AC Douds, MK Baig, C Page, M Yamada, JG Goldman, JD Maxwell,

W McKenna. St. George's Hospital Medical School,LondonSW17 ORE

Asymptomatic left ventricular enlargement (LVE) occurs in up to $30 \%$ of patients with alcoholic liver disease (ALD). The presence of IgG antibodies to cardiac acetaldehyde adducts in alcoholics suggests that immunological mechanisms may play a role in the pathogenesis of LVE. We postulate that other antigens such as cardiac myosin may also be important in the development of LVE.

Aims Our first aim was to determine if cardiac specific anti-alpha myosin antibodies are present in the sera of ALD patients. Secondly we investigated if these antibodies are associated with echocardiographic and signal average electrocardiographic (SAECG) abnormalities.

Methods Anti IgG alpha-myosin antibodies were assayed in: 51 consecutive ALD patients attending a liver clinic (age $52 \pm 9.9,36$ males) in 92 patients with ischaemic heart disease (age 56 $\pm 7.6,70$ males), and in 203 normals (age 45 $\pm 16,100$ males) using an ELISA. Patients with ALD also had 2D echocardiography and an SAECG.

Results Anti-IgG myosin antibodies were present in 9/51 (18\%) patients with ALD $\left(p<0.0001, \chi^{2}\right), 4 / 92(4 \%)$ patients with ischaemic heart disease $(p=0.44)$ compared to $4 / 203(2 \%)$ normals. Myosin antibodies were significantly more common in ALD $(P=0.02)$ than ischaemic heart disease patients. LVE was detected in $25 \%$ of patients with ALD and the SAECG was abnormal in 17\%. Anti myosin antibody positivity/ titres did not correlate with LVE or SAECG abnormalities in ALD patients.

Conclusion Myosin antibodies are significantly increased in patients with ALD. They are not common in those patients with established ECHO or SAECG abnormaltites suggesting that they do not occur simply as a consequence of myocardial damage. Myosin antibodies may be an early predictor of future development of LVE in patients with ALD.
DO PHARMACOLOGICAL AGENTS FOR PORTAL HYPERTENSION COMPROMISE RENAL FLOW?

Stanley A.J., Bouchier I.A.D., Hayes P.C.

Department of Medicine. Royal Infirmary of Edinburgh. EH4 9YW

Both propranolol (PROP) and isosorbide-5-mononitrate (ISMO) are commonly used in the management of portal hypertension. Rocently, concern has been expressed that these drugs may conpromise renal function in cirrhotic patients by reducing renal perfusion as a result of their hypotensive action. We assessed the haemodynamic effects including renal blood flow of these drugs.

Methods: 12 cirrhotic patients were studied. After an overnight fast, heart rate (HR), mean arterial pressure (MAP), hepatic venous pressure gradient (HPVG), azygous flow (AZY) and unilateral renal vein flow (RBF) (by direct reverse thermodilution method) were recorded. Patients were then given either 80mg PROP (6 patients, mean Childs-Pugh score (CPS) 9.2 (1.3)) or $20 \mathrm{mg}$ ISMO (6 patients, mean CPS 9.7 (1.7)) and the above measurements repeated after 60 minutes.

Results: There was no correlation between the baseline RBF and CPS although it was significantly reduced in patients with severe ascites $(p<0.01)$. Haemodynamic parameters at baseline (pre) and at 60 minutes (post) are summarised below:

\begin{tabular}{|l|ll|ll|}
\hline & \multicolumn{2}{|c|}{ PROP } & \multicolumn{2}{c|}{ ISMO } \\
\hline pre & $80.3(5.1)$ & post & pre & pet \\
\hline MAP & $80.5(4.9)$ & $75.8(4.2)$ & $87.7(3.8)$ & $91.2(4.1)$ \\
\hline HYPG & $18.8(2.7)$ & $13.8(2.6)$ & $83.7(4.2)$ & $76.3(4.8)^{\circ}$ \\
\hline AZY & $483.1(130.1)$ & $285.6(53.4) *$ & $614.2(261.9)$ & $591.7(209.7)$ \\
\hline RBF & $543.5(89.9)$ & $446.1(64.8)$ & $265.2(53.9)$ & $285.3(78.7)$ \\
\hline
\end{tabular}

Results are expressed as mean (standard error) with pressures in mmHg and fow in $\mathrm{ml} / \min$. ( $>0.05,{ }^{\circ} \mathrm{p}<0.01,{ }^{*} \mathrm{p}=0.001$ )

Conclusion: Despite the anticipated reduction in other haemodynamic parameters, RBF did not fall significantly following administration of either PROP or ISMO to cirrhotic patients.

\section{IBD and colorectal F228-F238}

F228

INCREASED EXPRESSION OF CIRCULATING LEUCOCYTE ADHESION MOLECULES CD11b AND CD18 IN INFLAMMATORY BOWEL DISEASE. CE Collins, C Davies*, MG Macey*, DA McCarthy*, DS Rampton. GI Science Research Unit and Department of Haematology*, St Bartholomew's and The Royal London School of Medicine and Dentistry, Whitechapel, London.

Adhesion of leucocytes to vascular endothelium depends in part on their expression of specific surface antigens. Among these, CD11 and CD18 bind to endothelial cell intercellular adhesion molecules-1 and -2. Leucocyte activation is a feature of inflammatory bowel disease (IBD) and monocyte-endothelial cell interaction may be an early event in pathogenesis. Conventional therapy including sulphasalazine may reduce expression of leucocyte adhesion molecules. We tested the hypothesis that IBD is associated with up-regulation of circulating leucocyte adhesion molecules.

METHODS: Using fluorescently-labelled specific monoclonal antibodies and a novel flow-cytometric method, we measured leucocyte surface expression of the antigens $C D 11 \mathrm{a}, \mathrm{b}$ and $\mathrm{c}$ and $\mathrm{CD} 18$ in unfixed whole blood in Crohn's disease (CD), ulcerative colitis (UC) and healthy controls.

RESULTS: No statistically significant differences in \% cells positive for these antigens were detected, but for $\mathrm{CD} 11 \mathrm{~b}$ and $\mathrm{CD} 18$, mean fluorescence intensity (MFI), a quantitative measure of antigen density, was increased for granulocytes (GNLs) and monocytes (MNs) in IBD.

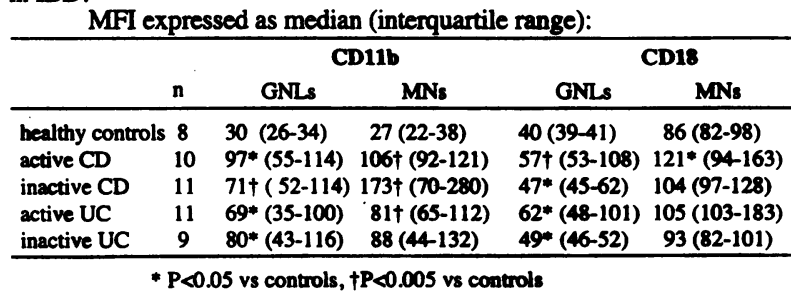

CONCLUSIONS: Increased expression of the adhesion molecules, CD11b and CD18, on circulating granulocytes and monocytes is likely, by enhancing leucocyte adhesion to vascular endothelium, to promote cellular diapedesis and infiltration of the bowel wall in IBD. 
INCREASED INDUCIBLE CYCLOOXYGENASE ASSOCLATED WTTH TRRATMINT FAIUURE IN ULCERATTVE COLTIS J McLenghlan', R Seth', AT Cole', BB Scott, D Jenkins', AR Robins', CJ Hawikey'. Divs 'Geutroenterology, 'Histopathology \& 'Immunology, University Hospital, Nottingham NG7 2UH, \& 'Lincoln County Hospital.

INTRODUCTION The cycloxygenase (COX)-2 gene is induced at sites of inflammetion and in colouic carcinom and normally suppressed by steroids. Since COX-2 could be important for maligmant change or prostaglandin dependent secretion in ulcerative colitis, we investigated COX-2 expression in colonic mucoenal enmples from patients with ulcerative colitis, and normal controls, and related results to expression of inducible nitric oxide synthase (iNOS) and interieukin (IL)-8 since these are normally co-induced.

MIETHODS Mucosal biopsy smples were obcained from 17 patients with ulcerative colitis (8 surgery, failed steroid response: 9 newly diagnosed, untreated). After RNA extraction (RNAzol) and reverse transcription, polymerace chain reaction (PCR) amplification of specific CDNA sequences for COX-2 (232 bare pairs, 23 cycles), iNOS (453 base pairs, 28 cycles), II-8 (220 base pairs, 23 cycles) and GAPDH (reference housckeeping gene, 650 base pairs, 23 cycles) was carn $: x d$ out and PCR product assayed using a semi quantitative enzyme linked oltgomucleotide chemilumineacent assay.

RESULTS PCR product levels (median and IQR) expressed as proportion of GAPDH ( $\times 10^{3}$ for COX-2) are shown in the table.

COX-2 II-8 iNOS

$\begin{array}{llll} & & (0.03-0.8) & (0.3-5.3) \\ \text { Ulcerative colitis }(\mathrm{n}=17) & 14(7-34) & 1.9 & 5.8 \\ & & (0.6-5.3) & (2.0-38.1) \\ \mathrm{P}(\mathrm{Mann} \text { Whitney) } & 0.016 & <0.001 & <0.05\end{array}$
Sub group analysis showed COX-2 PCR product levels were significantly elevated in patients having surgery for failed medical treatment [31 (13-38) vs $10(4-14), p=0.04)$ ], but not in newly diagnowed untreated patients $[10$ (7-34) vs 7 (5-13), $p=0.37$. COX-2 levels correlated with acuite inflammation and IL-8 $(R S=0.43, P=0.008)$ but not iNOS $(p=0.107)$.

CONCLUSTON COX-2 expression is enhanced in active ulcerative colitis. A sub group of patients, in whom medical treatment fails, may be resistant of the suppressive effects of steroids.

IMAGING OF E-SELECTIN, A SPECIFIC MARKER OF ENDOTHELIAL CELL ACTIVATION, IN THE EVALUATION OF INFLAMMATORY BOWEL DISEASE.

MA Bhatti, PT Chapman, AM Peters, DO Haskard, HJF Hodgson.

Royal Postgraduate Medical School, Hammersmith Hospital, Du Cane Road, London W12 ONN

E-Selectin expression is up-regulated in response to pro-inflammatory cytokines and makes an integral part of the process leading to accumulation of inflammatory cells in the tissue. Tissue E-Selectin expression is increased in Inflammatory bowel disease (IBD) and we have investigated its potential for targeting the inflammatory activity in IBD.

METHODS:

9 Ulcerative colitis (UC) and 7 Crohn's disease (CD) patients with varying degrees of active inflammation were selected with prior consent. Following intravenous administration of 111-Indium (111-In) labelled antibody to E-Selectin, anterior, posterior and lateral images were obtained $4 \mathrm{hrs}, 24 \mathrm{hrs}$ and $48 \mathrm{hrs}$ post injection by gamma camera equippesd with medium-energy-general-purpose collimator. A 99-Technetium (99Tc) labelled scan was performed the following day.

\section{RESULTS:}

9 out of 16 patients had active areas of inflammation, defined by 99-Tc labelled white cell scans. The extent of inflammation demonstrated by 111-In labelled E-Selectin scan ranged from pan-colitis in active UC to localised areas of inflammation both in UC and CD. 10 patients with active IBD had positive E-Selectin scans. The results were concordant in 9 and discordant in 3. Four patients were negative on both types of scans.

111-In labelled E-Selectin antibody images correlated well with the extent and activity of the disease, however the correlation with clinical indices of the level of severity of the disease was less significant. CONCLUSIONS:

We have demonstrated that E-Selectin scan can localise the area of inflammation through the process which is simpler than white cell scan. It is more versatile and can be done in neutropaenic patients.
PROGNOSTIC VALUE OF WHOLE GUT LAVAGE FLUID AMALYSIS IN CROHN'S DISEASE.

S Ghosh, Sabrina Accium, Anne Ferguson. Gastrointestinal Laboratory, Department of Medicine, University of Edinburgh, Westem General Hospital, Edinburgh EH4 2XU.

There are no reliable methods to determine the probability of relapse in Crohn's disease. Though prognostic indices based on ESR, $\alpha_{2}-$ globulin and $\alpha_{1}$ glycoprotwin have been designed to predict outcome, serum proteins poorty reflect mucosal immune events, and such indices have not generally been found useful. Anatysis of whole gut lavage fluid (WGLF) is an objective measure of activity of IBD, and gut immune events such as noutrophil migration and proinflamn attory cytokine production can be investigated. The aim of this sth's, was to investigate whether WGLF parameters are of prognostic relevance with respect to relapses of disease. Thinty patients with Crohn's disease were in remission (no symptoms, normal ESR, CRP, white cell count, WGLF IgG S $10 \mu \mathrm{g} / \mathrm{mL}$ ) at the time of whole gut lavage with potyethylene-glycol electroble (Klean-Prep) solution. Granulocyle elastase (GE), a marker of neutophils in WGLF was assayed using a highty specific substrate, L-pyroglutamyl-L-prolytL-valine-p-nitroanilide (Quadratech, UK). IL-1 $\beta$ in WGLF was assayed using a commercial ELISA kit (Cistron, USA). Twelve patients had detectable GE in WGLF, and 10 of them were not in remission at 1 year atter the inital lavage; 4 had a relapsing course (needing stercid therapy), 5 were steroid dependant and 1 was on immunosuppressive therapy. In contrast, 18 patients in remission had undetectable GE in WGLF, and 12 of them were in remission at 1 year needing no therapeutic intervention $(p<0.01)$. Ten of the patients in remission had detectable IL-1 $\beta$ in WGLF and 8 of them were not in remission at 1 year after the initial lavage; 3 had a relapsing course (needing steroid therapy), 4 were steroid dependant and 1 was on immunosuppressive therapy. In contrast, 19 patients had undetectable IL-1 $\beta$ in WGLF, and 12 of them were in remission at 1 year needing no therapeutic intervention $(p<0.01)$.

In conclusion, in Crohn's disease patients in remission, detectable GE or IL-1 $\beta$ in WGLF is associated with a poorer outcome at 1 year.
IN SITU IMMUNE RESPONSES IN CROHN'S DISEASE: A COMPARISON WITH ACUTE AND PERSISTENT MEASLES VIRUS INFECTION.

A.J.Wakefield R.Sim, A.Akbar', R.E.Pounder, A.P.Dhillon Inflammaron Bowel Disease Study Group and Department of Immunology. Roval Free Hospital School of Medicine, Rowland Hill Street. Hampstead. London N'W3 2PF, UK.

The implied aetiological association of measles virus with Crohn's disease would be supported by detection of an immune response to infecter cells in affected tissues. This study sought to detect and characterise in situ immune responses to measles virus in both acutely and persistently infected tissues, and in particular, Crohn's cranulo Serial tissue sections from cases of Crohn's disease $(n=17)$, tuberculosis $(n=9)$, acute intestinal ischaemia $(n=5)$, acute measles pneumonitis $(n=2)$, acute measles appendicitis ( $=1$ ), subacute sclerosing panencephalitis (SSPE; $n=1)$, and measles inclusion body encephalitis (MIBE; $n=1$ ), were examined. Single and double immunohistochemical labelling was performed to identify both cytotoxic lymphocytes (CD8, TIA. perforin, Leu 7, CD45RO. CD45RA) and macrophages (KP1) The relationship of these cells to measles infected cells was identified by double immunolabelling with anti-measles virus nucleoprotein antibody. In both acute measles appendicitis and SSPE, CD $8^{+} / \mathrm{TlA}^{+}$cytotoxic lymphocytes (CTL) targeted infected cells. In the other tissues that were positive for measles virus including Crohn's disease (13/17) - where staining was largely confined to granulomata, MIBE. fatal pneumonitis, and 1 tuberculous yranuloma. infected cells appeared to be targeted by macrophages rather CTL. The CTL in Crohn's granulomata were Leu $7^{\circ}$ and perforin /CD45RO (naive). CTL in both tuberculous and Crohn's granulomata were similar in their peripheral distribution. number and phenotype. The data suggest that measles-specific CTL responses may be attenuated in Crohn's disease compared with acute measles appendicitis and SSPE, and secondly, that an abnormal macrophage response to persistent measles virus infection of the intestine may result in granulomatous inflammation. 
DOSE LOADING WITH ORAL MESALAZINE: OPTIMISING DRUG CONCENTRATIONS IN THE MUCOSA E Hunenin, R Ajjan, N.Trudgill, S Riley. Dept of Gastroenterology, Northern General Hospital, Sheffield, U.K

Mesalazine based products are widely used in the maintenance of ulcerative colitis remisssion. However, the optimal dose remains unknown since dose-ranging studies have yielded conflicting results.

We have therefore studied steady-state kinetics and mucosal drug levels in healthy volunteers taking progressively larger doses of oral mesalazine. 12 subjects (7 male, aged 18-30), were given delayed release mesalazine $400 \mathrm{mg}$ tds for 7 days. Serial blood and rectal mucosal samples and urine and stool were collected over 24 hours. Following a drug free interval the same subjects repeated the protocol with $800 \mathrm{mg}$ tds and $1600 \mathrm{mg}$ tds. Samples were analysed for 5-aminosalicylic acid (5ASA) and N-acetyl-5ASA (NA5ASA) by HPLC. Median results are shown below (NASASA/5ASA)

$\begin{array}{llll}\begin{array}{l}\text { PlasmaAuc } \\ (\mu \mathrm{ghr} / \mathrm{ml})\end{array} & \begin{array}{l}\text { Urine } \\ (\mathrm{mg})\end{array} & \begin{array}{l}\text { Freces } \\ (\mathrm{mg})\end{array} & \begin{array}{l}\text { MucosaAuc } \\ \text { (nghr/mg) }\end{array} \\ 17.2 / 3.9 & 249.8 / 1.8 & 361.9 / 124 & 92.8 / 22 \\ 30.9 / 15.4 & 523.7 / 85.5 & 242.7 / 420 & 169.2 / 81 \\ 56.8 / 46.8 & 1468 / 444.6 & 269.3 / 714 & 200.8 / 129\end{array}$

1600 tds $56.8 / 46.8 \quad 1468 / 4$
(AUC=area under curve)

Following serial dose-doubling with oral mesalazine :i) Combined faecal and urinary excretion (5ASA+NA5ASA) increase pro rata. ii) Urinary excretion (5ASA+NA5ASA) progressively exceeds faecal excretion. iii) The proportion of SASA to NASASA increases indicating saturation in urine, plasma, stool and rectal mucosa. iv)At higher dose, the increase in rectal mucosal levels is modest in comparison with the increase in plasma concentration and urinary excretion.
HLA-DR AND DO AND P.ANCA STATUS IN PATIENTS WITH AND WITEOUT POUCHTIS. N Yagnda* HJ Ellis, F Herbst*, J Nicholls* and PJ Ciclitira. Gastroenterology Unit, UMDS St. Thomas' and 'St. Mark's Hospitals London.

Background. Pouchitis, diagnosed by histological and clinical criteria, occurs at some time in over a third of patients with an ileoanal pouch fashioned after colectomy for ulcerative colitis (UC). We have studied HLA-Class II and p-ANCA as markers for the development of pouchitis.

Methods. HLA-DR and DO were examined in patients with $(n=25)$ and without $(n=28)$ pouchitis following restorative proctocolectomy for UC. Peri-nuclear anti-neutrophil antibody (pANCA) was assessed in a sub-group of patients with $(n=22)$ and without $(n=16)$ pouchitis. The HLA-DR and DO alleles were determined by PCR-SSP typing and p-ANCA status by indirect immunofluoresence. Normal healthy laboratory staff $(n=15)$ were assessed as controls for p-ANCA status.

Results. The haplotype DRB1*0301, DQB1*0201 was present in $36 \%$ of pouchitis patients and $29 \%$ of patients without pouchitis. p-ANCA was present in $45 \%$ of patients with pouchitis and $38 \%$ of those without (n.s.). p-ANCA was not detected in any normal controls; this result was significantly different from patients without pouchitis $(p=0.011)$ and with pouchitis $(p=0.002)$.

Discussion. Our results suggest that there is no difference in HLA DR and DQ alleles possessed by those UC patients who, after restorative proctocolectomy, develop pouchitis and those who do not. The single largest haplotype possessed by the two groups, $\mathrm{DRB} 1 * 0301, \mathrm{DQB} 1 * 0201$, encoding the serological type, DR3, DQ2, is also possessed by $24 \%$ of the normal UK population, suggesting that these alleles cannot be used to predict the development of either UC, or pouchitis. Our results do not agree with those of Satsangi et al (Gut 37(2) A21) which suggest that HLA Class II genes are important in susceptibility to UC. Our results also reveal p-ANCA occurs in individuals with UC both with and without pouchitis and serves as a marker of UC but not pouchitis, remaining elevated in patients with UC despite restorative proctocolectomy.

\section{PSYCHOLOGICAL MORBIDITY IN INTLAMMATORY} BOWEL DISEASE-THE IMPACT OF A COUNSELLING SERVICE.

Smith GD. Luman W, Roger D, Palmer KR. Gastrointestinal Unit, Western General Hospital, Edinburgh.

It is often assumed that counselling may alleviate many of the psychological problems associated with Crohn's disease (CD) and ulcerative colitis (UC) although this has not been proven.

Fifty patients with CD (38 females,median age 38), 50 UC patients (22 females, median age 38) and a group of 50 healthy volunteers ( HV, 27 females, median age 34) underwent structured interviews and completed a range of questionnaires measuring several facets of psychological wellbeing ( Hospital Anxiety and Depression Score (HAD), Attitudes \& Preferences(AP) and Styles \& Strategies(SS) questionnaire). Patients with $C D$ and UC were then randomised to receive either a counselling package or routine clinical follow-up. The counselling package consisted of disease specific educational videos, information booklets and the teaching of stress management techniques. Patients were reassessed at six months.

At baseline,the scores for HAD, SS and AP were within the normal range in patients with UC and HV. CD patients had higher anxiety level than HV (mean anxiety score CD 10.1,UC 7.7, HV 6.8, p<0.001). CD patients also demonstrated significant maladaptive coping mechanism on SS score (mean maladaptive score CD 19,UC 15, HV $12, p<0.001)$. At follow-up, the anxiety score of counselled CD patients improved significantly $(p<0,005)$ as did their maladaptive coping mechanism $(\mathrm{p}<0.005)$.

Psychological morbidity is common in CD and can be quantified using validated questionnaires. These aspects of psychological morbidity can be effectively treated by specific counselling.
A COMPARATIVE STUDY TO INVESTIGATE FACTORS ASSOCIATED WITH IRREGULARITIES OF BOWEL FUNCTION AMONG HEALTHY BENGALIS IN CALCUTTA AND SHEFFIELD AND ENGLISH SUBJECTS IN SHEFFIELD. S.SENGUPTA, N.W.READ. CENTRE FOR HUMAN NUTRITION, NORTHERN GENERAL HOSPITAL, SHEFFIELD S5 7AU. U.K

INTRODUCTION Factors underlying irregular bowel habits (IBH) are unknown but previous studies have implicated gender and diet. These may vary in different cultural groups, as studies in the UK report that more females than males $(2: 1)$ have Irritable bowel syndrome (IBS) while in India, it seems that more males than females (3.5:1) have IBS.

AIMS To investigate the prevalence of IBH in the healthy general population from India and UK and explore how patterns of bowel habit are related to different cultural background, gender, psychological factors and patterns of eating and other behaviours.

METHODS A questionnaire on bowel habits, eating behaviour, mood and other behaviours was completed by 318 Bengalis in Calcutta ( $156 \mathrm{M}$ and $159 \mathrm{~F}$ ) and 108 Bengalis in Sheffield ( $51 \mathrm{M}$ and $57 \mathrm{~F}$ ) and 233 English in Sheffield (101 M and 132 F).

RESULTS $52.7 \%$ of Bengalis in Calcutta reported IBH compared with 45.4\% Bengalis and 49.8\% English in Sheffield. IBH was more common in female English subjects in UK (m:f ; 39:77) and in male Bengalis in Sheffield (m:f; 32:17) and Calcutta (m:f ; 97:69). A greater percentage of Bengalis and English with IBH than those with regular bowel habit (RBH) reported inconsistent meal timings, frequent snacking, breakfast skipping, frequent micturition, and sleep disturbence. None of these could account for the gender specificity of bowel habit within the three populations. Other fectors more common in Bengalis with IBH which could account for male preponderance were consumption of tea, coffee, alcohol and beetle leaf, smoking and marital status. $72 \%$ of male Bengalis in Calcutta and $63 \%$ of male Bengalis in Sheffield with IBH were married compared with only $44 \%$ Bengali males in Calcutta and $26 \%$ Bengali males in Sheffield with RBH. Frequen mood change (FMC) was also more common in IBH subjects from all three groups and showed a female preponderance among the English subjects and a male preponderance among the Bengalis in Sheffield and Calcutta.

CONCLUSION An association between IBH and irregularities of several different behaviours and mood was obeerved in all three groups, though the data suggest that marital status, consumption of stimulants and alcohol consumption and FMC are all associatod with the male preponderance within the Bengalis with $\mathrm{BH}$. 
WHEN IS A RECTOCELE SIGNIFICANT?

Kumar $D$, Benson $M^{*}$, Grant $E$, Britton $A^{\prime}$, Gains $G^{*}$, Jazrawi $R^{*}$, Joseph $A^{\prime}$. Departments of Colorectal Surgery, Gastroenterology* and Rediology", St George's Hoepital, Tooting, London, UK.

Rectoceles are commonly investigated by barium proctography This is a qualitative investigation and does not provide data on rectocele emptying. We have used a quantitative method [isotope defaecography (ID)] with the aim of differentiating between significant (SR) and non-significant rectoceles (NSR).

We studied 95 patients with a clinical diagnosis of rectocele. ID was performed using $100 \mathrm{Mbq}$ of "Tc mixed with $100 \mathrm{mls}$ of oat porridge. 71 of the 95 patients were found to have a rectocele. The percentage and rate of evacuation $(\% / \mathrm{sec})$ and also the percentage of isotope retained in the rectocele were calculated. Patients with $15 \%$ or more retention in the rectocele were defined as having a significant rectocele.

Results: 34 of 71 had a significant rectocele. The SR group had a significantly higher retention of the isotope than NSR [22.3 (1.4) vs $9.6(0.4), p<0.0005)$. Similarly the retention of the isotope as percentage of final rectal content was significantly higher in the SR than NSR group [52.6 (2.4) vs $33.1(1.8)], p<0.0001]$. The rate of evacuation in the two groups was similar $[0.97(0.1)$ vs 1.3 $(0.1), p>0.05]$. There was no significant difference in the total percent evacuation between the no rectocele and NSR groups. There was a significant correlation between the presence of a significant rectocele and total percentage evacuation $(r=0.61$, $p<0.0001)$. There was no significant correlation between the presence of a SR or NSR and the rate of evacuation.

These data suggest that retention of $15 \%$ or more of the rectal contents in the rectocele influences the total percent evacuation resulting in impaired defaecation. This may be a useful way of differentiating between significant and non-significant rectoceles and selecting patients for surgical therapy.
EARLY INDOMETHACIN LESIONS IN RAT JEJUNUM: REDUCED FOCAI BLOOD FLOW AND SHORTENING O VILI FR CCIDE ULCERATION. D. Kelly, C. Piasecki. A. Anthony RE Pounder, AJ Wakefield. Royal Free Hospital and Medical School, London. UK.

Background. Histologically, administration of indomethacin (indo) causes villus shortening eosinophil infiltration and microvascular distortion prior to ulceration. These changes may compromise blood flow distortion, prior to uiceration.

Aim. This hypothesis was tested by correlating histological changes with Aim. This hypothesis was tested by correlating histological changes with changes in

Methods. In two groups of rats ( $n=5$ per group), oral indo ( $15 \mathrm{mg} / \mathrm{Kg}$ ) was given at 4 or $6 \mathrm{~h}$ preoperatively. Luminal and plasma levels wer measured in order to determine the optimum dosing for subsequen experiments. After anaesthesia exterionised villi enclosed in a chamber were observed by fluorescent microscopy using iv FITC dextran and labelled red cells. Blood flow in surface arcade vessels was calculated from measurements of velocties and diameters $\left(b f=\pi / 4 . v \cdot d^{2}\right)$. In other groups indo was applied by simultaneous topical $(100 \mu \mathrm{g} / \mathrm{ml})$ and iv administration (producing a peak plasma level of $100 \mu \mathrm{g} / \mathrm{ml})(\mathrm{n}=5)$ Controls consisted of vehicle alone $(n=5)$. Animals were sacrificed perfusion fixed with $5 \%$ formol saline and processed for histology. Results. Oral indo resulted in peak luminal and plasma indo concentrations of $100 \mu \mathrm{g} / \mathrm{ml}$. In-vivo observation revealed groups of villi with vascular stasis. Hustologically the villi were shortened and had ${ }^{4}$ with vascular stasis. Histologically the vilted epithelium and vessels. Combined
Controls topical and iv indo, given per-operatively. Controls topical and iv indo, given per-operatively 2.H blood flow in individual villi, and complete Indo stasis within 15-45 mins in individual villi ${ }_{0} \underbrace{}_{30} \begin{gathered}\text { Indo } \\ 90\end{gathered}$ with distortion (but no loss) of surface epithelium overlying foci of vascular stasis, and normal surrounding villi. In both regimens lesions occurred only on the mesenteric border animals had normal blood flow $(2.6 \pm 0.1 \mathrm{nl} / \mathrm{min})$ for $1.5 \mathrm{hrs}$

Conclusions. Oral dosing with indo, or combined topical and iv dosing at an ulcerogenic level, produces pre-ulcerative villus shortening, associated with severe focal interference of capillary blood flow. Thus focal ischaemic changes are likely to be involved in induction of lesions Funded by Glaxo-Wellcome Plc.
DETECTION OF FAECAL INCOIVTINENT EPISODES USING A NEW AMBULATORY WETNESS DETECTOR

J. Gunn, R. Farouk, J.R.T. Monson, G.S. Duthie ; University of Hull, Academic Surgical Unit, Castle Hill Hospital, Cottingham, North Humberside.

Internal anal sphincter ambulatory assessment has suggested the anorectal pressure gradient may be reversed during faecal soiling. However patiehts are commonly unable to perceive these events. The aim of this study was to develop a wetness detector that would allow us to identify objectively episodes of faecal incontinence.

The wetness detector was constructed from a $5 \mathrm{~mm}$ catheter with two copper electrodes set $3 \mathrm{~cm}$ apart. A low voltage AC current was passed down the catheter and when the moisture levels increased, then electrical resistance between the two electrodes would reduce allowing an increase in conductivity indicating faecal incontinence. Simultaneous anorectal manometry was performed to correlate these events with changes in the anorectal pressure gradient.

10 patients (median age 58, range 44-76) with faecal incontinence were assessed for a median of 8 (4-18) hours. Episodes of faecal leakage were detected in all patients characterised by a rise in conductivity. A positive recto-anal pressure gradient was recorded for all of these events.

In conclusion, a sensor has been developed which can accurately and objectively detect episodes of faecal incontinence. The ability to detect occult episodes of faecal leakage has clear implications for the assessment of patients complaining of faecal incontinence.
SERUM SUCROSE. A NEW SCREENING TEST FOR COELIAC DISEASE.

M A Cox, T H Iqbal,.K O Lewis, B T Cooper.

Gastroenterology Unit, City Hospital, Dudley Road, Birmingham. B18 $7 \mathrm{QH}$.

An accurate non invasive test to screen for coeliac disease (CD) would be popular with patients and reduce the need for small bowel biopsy. Until recently such tests were inaccurate. IgA endomysial antibodies have been found to have a high sensitivity and specificity for CD. Small intestinal permeability tests involving urinary recovery of ingested markers are highly sensitive but not specific for CD.During the development of techniques to measure permeability in serum, an unidentified peak was found in the serum from untreated $C D$ patients but not in other sera. This peak was later found to be sucrose. The aims of this pilot study were to determine if serum sucrose is a marker for untreated CD and to compare the results with endomysial antibody titres. 20 consecutive newly diagnosed coeliacs, 15 celiacs on a strict gluten free diet for more than 12 months and 15 healthy normal controls were studied. All were given a drink containing approximately $8 \mathrm{~g}$ of sucrose and had blood taken 30-45 minutes later: serum was deproteinised using the method of Somogyi and analysed using HPLC and pulsed amperometric detection for the presence or absence of sucrose (Proc Ass Clin Biochem 1995 A82:89-90). Sucrose was present in all 20 untreated coeliacs but in none of the treated coeliacs or normal controls. 17 untreated coeliacs were endomysial antibody positive; all the treated coeliacs and normal controls were negative. Serum sucrose separated untreated coeliacs from treated coeliacs and normal controls more accurately than endomysial antibodies. Serum sucrose shows promise as an indirect marker of villous atrophy and coeliac disease. 